\title{
OS DESAFIOS DA PESQUISA NO ALTO SERTÃO PARAIBANO: ENSINO E APRENDIZADO DA PESQUISA NO CURSO DE PEDAGOGIA DO $\mathrm{CFP} / \mathrm{UFCG}^{1}$
}

\author{
Maria José Sousa Brito \\ Universidade federal de Campina Grande (UFCG), \\ mariajusb@gmail.com
}

\begin{abstract}
RESUMO
O artigo é um recorte do trabalho de pesquisa em desenvolvimento no curso de Pedagogia do Centro de Formação de Professores da Universidade Federal de Campina Grande - CFP/UFCG. A questão central pontuada no presente artigo é sobre como a literatura vem tratando o ensino da pesquisa na última década, considerando a década de ensino da pesquisa no CFP/UFCG, recriado em 2004. O objetivo é discutir as estratégias de ensino da pesquisa na formação inicial do pedagogo, e sua tendência. A abordagem será qualitativa com coleta de dados na Tabela de análise de textos acadêmico-científicos das dimensões de pesquisa propostas por Novikoff (2010) - TABDN. A análise de conteúdo será empregada junto com categorias a priori "conhecimento" em suas diferentes vertentes (pedagógico, teórico, normativo, metodológico, profissional, sócio relacional e outro). Espera-se contribuir com a disseminação do valor da pesquisa para a formação do pedagogo.
\end{abstract}

PALAVRAS-CHAVE: Pesquisa. Formação de Professores. Conhecimentos.

\section{THE CHALLENGES OF RESEARCH IN THE HIGH PARAIBAN SERTÃO: TEACHING AND LEARNING OF RESEARCH IN THE COURSE OF PEDAGOGY OF THE CFP / UFCG}

\begin{abstract}
The article is a review of the research work under development in the pedagogy course of the teacher training center of the federal university of campina grande - cfp / ufcg. The central issue pointed out in this article is about how literature has been treating research teaching in the last decade, considering the decade of research teaching at the cfp / ufcg, recreated in 2004. The objective is to discuss the teaching strategies of research in formation of the

\footnotetext{
${ }^{1} \mathrm{O}$ presente trabalho (não) contou com apoio financeiro de nenhuma natureza para sua realização.
} 
pedagogue, and his tendency. The approach will be qualitative with data collection in the table of analysis of academic-scientific texts of the research dimensions proposed by novikoff (2010) - tabdn. Content analysis will be used along with a priori "knowledge" categories in its different aspects (pedagogical, theoretical, normative, methodological, professional, relational partner and other). It is hoped to contribute to the dissemination of the value of research to the education of the pedagogue.

Keywords: research. Teacher training. Knowledge.

\section{LOS DESAFÍOS DE LA INVESTIGACIÓN EN EL ALTO SERTÓN}

\section{PARAIBANO: ENSEÑANZA Y APRENDIZA DE LA INVESTIGACIÓN EN EL CURSO DE PEDAGOGÍA DEL CFP / UFCG}

\section{RESUMEN}

El artículo es un recorte del trabajo de investigación en desarrollo en el curso de Pedagogía del Centro de Formación de Profesores de la Universidad Federal de Campina Grande - CFP / UFCG. La cuestión central puntuada en el presente artículo es sobre cómo la literatura viene tratando la enseñanza de la investigación en la última década, considerando la década de enseñanza de la investigación en el CFP / UFCG, recreado en 2004. El objetivo es discutir las estrategias de enseñanza de la investigación en la formación El pedagogo, y su tendencia. El enfoque será cualitativo con la recolección de datos en la Tabla de análisis de textos académico-científicos de las dimensiones de investigación propuestas por Novikoff (2010) TABDN. El análisis de contenido se empleará junto con categorías a priori "conocimiento" en sus diferentes vertientes (pedagógico, teórico, normativo, metodológico, profesional, socio relacional y otro). Se espera contribuir a la diseminación del valor de la investigación para la formación del pedagogo.

PALABRAS CLAVE: Búsqueda. Formación de profesores. Conocimientos.

INTRODUÇÃO 
Este trabalho propõe apresentar parte do estudo sobre o ensino de pesquisa na formação de professores. Ao entender a pesquisa como essencial no desenvolvimento da docência, diante das tecnologias e do avanço da ciência, faz-se oportuno, também, estabelecer novas práticas para intervir no processo de ensino e aprendizagem, alicerçadas nas atividades acadêmicas.

A pesquisa como suporte para formação do Pedagogo é imprescindível para se estabelecer novas práticas pedagógicas frente ao ensino da pesquisa, bem como conhecer informações e conhecimentos que possibilitem ao Pedagogo se tornar um bom profissional na sua área de atuação.

A proposta nesse artigo é discutir a formação de professores na literatura vigente e o lugar da pesquisa nesse contexto

O ensino de pesquisa na formação de professores

A formação de educadores, ainda acontece de forma superficial, sem a pesquisa científica, tendendo a uma racionalidade instrumental (GATTI, 2000; 2014a, 2014b; ANDRÉ et al., 2006). Com o processo de pesquisa científica é possível estabelecer práticas pedagógicas que transforme o conhecimento, através de 'uma metodologia consciente', capaz de dinamizar as práticas pedagógicas e criar novos conhecimentos, sair da zona de conforto e buscar inquietações que levante novas questões ao conhecimento.

Diante do exposto surge a necessidade compreender se o ensino de pesquisa atende as exigências da formação de professores?

O texto descreve a pesquisa na formação docente e discute a importância da pesquisa para a formação inicial de professor. Os transcritos sobre a formação de professores atingem uma alta produção, o que nos remete a expressar que há uma manifestação das questões: profissionais, políticas, trabalhistas e epistemológicas. A formação de professores atinge um campo vastíssimo que vai da formação inicial até as bases políticas. Uma profissão que exige saberes, valorização, ética, conhecimento, autonomia e serviço dedicado a sociedade. (MEDEIROS, 2005).

Dessa forma, a formação docente é capaz de desenvolver no aluno o pensamento científico, o desejo de realizar pesquisa. $\mathrm{O}$ ensino e a pesquisa estão entrelaçados podem desenvolver ações que superem os desafios atuais da educação. Como nos esclarece Novikoff 
(2011). Acrescento que a pesquisa nos cursos de formação deva ser mais bem trabalhada em prol de ações que possam superar as deficiências educacionais vigentes.

A experiência com o ensino de pesquisa no ensino superior enriquece a produção acadêmica, além de constituir saberes essenciais para a formação do pedagogo/ docente/ pesquisador. Desse modo, objetiva discutir a importância do ensino de pesquisa para a formação do pedagogo.

A pesquisa e as ações pedagógicas facilitam a atuação do aluno e do pesquisador com o conhecimento e desenvolve práticas científicas mais comprometidas com desenvolvimento e autonomia do aluno e com sua formação de pesquisador.

A pesquisa integrada as ações pedagógicas nos remete a pensar o ensino que vivenciamos - o tradicional. Para que se obtenha sucesso, é necessário repensar o ensino dando a ele um novo significado que tenha relação com a pesquisa, assim será possível desenvolver um ensino de qualidade. Mesmo com, o modelo atual de educação apresenta sinais enfraquecimento metodológico e na formação de educadores, pois o novo cenário histórico, social, econômico e político vêm sofrendo modificações e requer novos pensamentos que supere as concepções atuais.

A pesquisa na formação de professores, nos últimos anos passa por investigações de vários teóricos entre eles: Gatti, Medeiros, Novikof. As abordagens teórico- metodológicas nos faz refletir sobre o conhecimento advindo da academia, com sua capacidade de criação, bem com a capacidade de auxiliar o processo de pesquisa na formação inicial dos professores. O pesquisador docente universitário competente tem o compromisso de coordenar os futuros educadores pesquisadores, apresentando um contexto teórico capaz de gerar conhecimentos e transformar as práticas dos indivíduos. A docência acontecendo através da pesquisa resulta na manifestação de novos estudos, que instigam o pensamento e a capacidade crítica do educador.

A desvalorização do docente se inicia com a profissionalização que não é bem regulamentada, assim a profissionalização desse profissional, na maior parte, os sistemas não proporcionam a elaboração dos planos de cargos e carreira, não se realiza como deveria (GATTI; BARRETTO; 2009; GATTI; BARRETTO; ANDRÉ, 2011).

A formação de professores deve ressaltar dois pontos marcantes: o ensino de pesquisa e o entendimento da pesquisa, para que aconteça uma mudança do ensino de pesquisa nas 
universidades (NOVIKOFF, 2011). Com isso a pesquisa cientifica precisa ser e entendida como um exercício de (re) elaboração realidade, visto que é uma atividade de aprendizagem que se ocupa com a realidade. A pesquisa, assim entendida pode ser "compreendida como um processo de produção de conhecimentos para a compreensão de uma dada realidade, isto é, de conhecimentos que nos auxiliem na interpretação da realidade vivida" (TOZONI-REIS, p.2, 2017).

Considero que o ensino de pesquisa necessite ser mais elaborado, pensado de forma científica, para atender as transformações e produções acadêmicas. É importante destacar a importância do ensino de pesquisa para o conhecimento na área da Educação como vem apontando Gatti (1998; 2002; 2003), pois a pesquisa possibilita novos conhecimentos, como também para desenvolver no sujeito pesquisador o pensar, e a criticidade.

\section{METODOLOGIA}

Para o trabalho em estudo vem sendo utilizada a Tabela de Análise de Textos Acadêmicos e Científicos das Dimensões de pesquisa propostas por Novikoff - TABDN que se divide em cinco dimensões. São elas:

1) A dimensão epistemológica que visa definir o objeto a partir da sua problematização e delimitação. Portanto, além desses elementos, elabora-se o objetivo, a hipótese ou pressupostos no caso de pesquisa qualitativa.

2) A dimensão teórica versa sobre a revisão da literatura com a finalidade de sustentar o estudo com base no aprofundamento de conceitos e teorias balizadoras do estudo.

3) Na dimensão técnica é detalhada a metodologia do estudo e suas técnicas de coleta de dados e de análise.

4) Segue a dimensão morfológica, onde se descreve os resultados do estudo coletado e se fixam as formas de sua exposição, como por exemplo, apresentar os dados em forma de gráficos, tabelas, ou narrativas.

5) $\mathrm{Na}$ dimensão analítico-conclusiva o pesquisador confronta os dados coletados e apresentados na dimensão anterior com a teoria e aos objetivos propostos. Responde as questões elaboradas e apresenta as conclusões. 
As tabelas corroboram com o trabalho científico ao nortear cada etapa da pesquisa e ao permitir, concomitantemente, averiguar o cuidado dos autores nos esclarecimentos de cada fase do seu estudo.

\section{RESULTADOS}

\begin{tabular}{|c|c|c|c|}
\hline tor & Artigo & Formação de professores & Professor pesquisador \\
\hline $\begin{array}{l}\text { Marly Krüger } \\
\text { de Pesce } \\
\text { Marli Elisa } \\
\text { Dalmazo } \\
\text { Afonso de } \\
\text { André }\end{array}$ & $\begin{array}{l}\text { Formação } \\
\text { professor } \\
\text { pesquisador na } \\
\text { perspectiva do } \\
\text { professor formador }\end{array}$ & $\begin{array}{l}\text { A formação de professores } \\
\text { não pode ser pensada a partir das } \\
\text { ciências e seus diversos campos } \\
\text { disciplinares, como adendo destas áreas, } \\
\text { mas a partir da função social própria à } \\
\text { escolarização - ensinar às novas } \\
\text { gerações o conhecimento acumulado e } \\
\text { consolidar valores e práticas coerentes } \\
\text { com nossa vida civil (GATTI, 2010, p. } \\
\text { 1375). }\end{array}$ & $\begin{array}{l}\text { A formação do professor } \\
\text { pesquisador significa proporcionar a } \\
\text { construção de uma forma de pensar curiosa, } \\
\text { observadora, reflexiva e analítica. Ou seja, há } \\
\text { um entendimento de que os futuros } \\
\text { professores devam saber como investigar os } \\
\text { conteúdos do campo disciplinar e da docência; } \\
\text { tendo a capacidade de elaborar questões, de } \\
\text { formular, de selecionar e articular dados, } \\
\text { levando à construção de um pensamento } \\
\text { reflexivo e investigativo. } \\
\text { ANDRÉ2012, p.49) }\end{array}$ \\
\hline $\begin{array}{l}\text { Selma } \\
\text { Garrido } \\
\text { Pimenta }\end{array}$ & $\begin{array}{l}\text { Pesquisa-ação } \\
\text { crítico-colaborativa: } \\
\text { construindo seu } \\
\text { significado a partir } \\
\text { de experiências com } \\
\text { a formação docente }\end{array}$ & $\begin{array}{l}\text { Conforme Zeichner (1993), a } \\
\text { formação passa sempre pela mobilização de } \\
\text { vários tipos de saberes: saberes de uma prática } \\
\text { reflexiva, saberes de uma teoria especializada, } \\
\text { saberes de uma militância pedagógica (Pimenta, } \\
\text { 1997). E conforme } \\
\text { Nóvoa (1992), o processo de formação crítico- } \\
\text { reflexivo implica em produzir a vida do } \\
\text { professor (desenvolvimento pessoal), produzir a } \\
\text { profissão docente (desenvolvimento } \\
\text { profissional)e produzir a escola } \\
\text { (desenvolvimento organizacional). } \\
\text { A formação constitui não só um processo de } \\
\text { aperfeiçoamento profissional, mas também um } \\
\text { processo de transformação da cultura escolar, } \\
\text { em que novas práticas participativas e de } \\
\text { gestão democrática vão sendo } \\
\text { implementadas e consolidadas. } \\
\text { Nesse sentido, a formação de professores } \\
\text { reflexivos configura um projeto pedagógico } \\
\text { emancipatório (Kincheloe, } \\
\qquad 1997 \text {; Pimenta, 1998, 1999). }\end{array}$ & Não encontrado \\
\hline
\end{tabular}

Revista de Pesquisa Interdisciplinar, Cajazeiras, n. 2, suplementar, p. 294-306, set. de 2017. 


\begin{tabular}{|c|c|c|c|}
\hline $\begin{array}{l}\text { BRUM, Luíza } \\
\text { Ribeiro } \\
\text { (UEM) } \\
\text { ASPARIN, } \\
\text { João Luiz } \\
\text { (UEM) }\end{array}$ & $\begin{array}{lr}\text { Formação } & \text { de } \\
\text { professores: } & \text { um } \\
\text { olhar sobre } & \text { a } \\
\text { docência } & \text { com } \\
\text { pesquisa } & \end{array}$ & $\begin{array}{l}\text { Nunes (2001), quanto à formação do } \\
\text { professor, descreve que há a consideração } \\
\text { de que o docente, ao longo de sua vida, } \\
\text { constrói e reconstrói seus conhecimentos com } \\
\text { base nos seus saberes e experiências. A autora } \\
\text { afirma que a discussão internacional } \\
\text { sobre a formação do professor ganhou } \\
\text { mais intensidade nas décadas de } 1980 \text { e } 1990 \text {. } \\
\text { No } \\
\text { Brasil, também é a partir de } 1990 \text { que há } \\
\text { mais enfoque nesse assunto, pois mais } \\
\text { pesquisas sobre a prática do professor e } \\
\text { dos saberes docentes surgiriam. Gohn (2005 } \\
\text { afirma que o trabalho docente e a formação de } \\
\text { professores devem estar interligados, uma vez } \\
\text { que o sucesso do trabalho depende diretamente } \\
\text { da boa formação e do saber elaborado que } \\
\text { corresponda ao que a sociedade espera. No } \\
\text { entanto, para desenvolver um trabalho que vá } \\
\text { ao encontro dos ideais sociais, faz-se necessária } \\
\text { aexigência de uma visão sobre as constantes } \\
\text { mudanças no meio educacional. }\end{array}$ & Não encontrado \\
\hline $\begin{array}{lll}\text { Sanny } & \text { s. Da } \\
\text { rosa* } & & \\
\end{array}$ & $\begin{array}{l} \\
\text { sentido da pesquisa } \\
\text { na formação inicial } \\
\text { de professores: } \\
\text { políticas e práticas } \\
\text { do curso de } \\
\text { pedagogia }\end{array}$ & $\begin{array}{l}\text { Ao se referir ao perfil do licenciado } \\
\text { em Pedagogia o texto que deu origem às } \\
\text { diretrizes curriculares nacionais do curso prevê } \\
\text { que ele deverá estar apto a: "estudar, aplicar } \\
\text { criticamente as diretrizes } \\
\text { curriculares e outras determinações legais que } \\
\text { lhe caiba implantar, executar, avaliar } \\
\text { e encaminhar o resultado de sua avaliação a } \\
\text { instâncias competentes" (Brasil, 2006,grifo } \\
\text { nosso). }\end{array}$ & $\begin{array}{l}\text { Assim, a discussão sobre a quem se } \\
\text { destina o discurso do "professor-pesquisador" } \\
\text { nos parece relevante especialmente se } \\
\text { quisermos, de fato, enfrentar a questão a } \\
\text { respeito da inclusão da pesquisa nos currículos } \\
\text { de graduação em Pedagogia, se pode e deve } \\
\text { ser perseguida como uma meta para melhorar } \\
\text { a qualidade da educação ou se permanecerá } \\
\text { como um mito, originalmente produzido no } \\
\text { interior dos discursos acadêmicos, arti€ } \\
\text { cialmente incorporados ao discurso o€ cial. É } \\
\text { por isso que, em nosso entendimento, se faz } \\
\text { indispensável saber de quem estamos falando, } \\
\text { ou seja, conhecer mais de perto a trajetória de } \\
\text { vida desse grande contingente de estudantes } \\
\text { que, embora tenham alcançado os bancos } \\
\text { universitários, permanecem "excluídos" da } \\
\text { vida acadêmica e cientí€ ca. Isto porque, } \\
\text { querendo ou não, são eles que constituirão a } \\
\text { próxima geração de professores de ensino } \\
\text { fundamental das escolas públicas brasileiras. }\end{array}$ \\
\hline $\begin{array}{l}\text { Soares, Kátia } \\
\text { Cristina } \\
\text { Dambiski-- } \\
\text { UFSC }\end{array}$ & $\begin{array}{l}\text { Trabalho e formação } \\
\text { docentes: tendências } \\
\text { no plano das } \\
\text { Políticas e da } \\
\text { literatura } \\
\text { especializada }\end{array}$ & $\begin{array}{l}\text { Em contrapartida, procuramos } \\
\text { desenvolver estudos voltados à formação dos } \\
\text { professores ancorada na reafirmação do } \\
\text { trabalho docente e daquilo que lhe é decorrente: } \\
\text { a função de ensinar e transmitir conhecimentos } \\
\text { e o papel da escola em socializar/democratizar o }\end{array}$ & $\begin{array}{l}\text { Facci }(2003) \text { alerta que existem } \\
\text { diferentes abordagens sobre este tema } \\
\text { (professor-investigador, professor- } \\
\text { pesquisador, prático-reflexivo, escola } \\
\text { reflexiva...), }\end{array}$ \\
\hline
\end{tabular}

Revista de Pesquisa Interdisciplinar, Cajazeiras, n. 2, suplementar, p. 294-306, set. de 2017. 


\begin{tabular}{|c|c|c|c|}
\hline & & $\begin{array}{l}\text { conhecimento } \\
\text { Compreende-se que no } \\
\text { quadro das relações sociais capitalistas, a } \\
\text { questão do trabalho docente - suas concepções } \\
\text { e efetivações - é basilar para o entendimento } \\
\text { das tendências que se explicitam no campo das } \\
\text { políticas educacionais e da literatura } \\
\text { especializada. } \\
\text { Na formação dos professores se cinde o que é } \\
\text { inseparável: teoria e prática, conteúdo e } \\
\text { método. A formação dos professores é } \\
\text { aligeirada, fragilizada esvaziada de conteúdo, } \\
\text { de conhecimento, em seu sentido mais amplo: } \\
\text { reduz-se ou mesmo nega-se a possibilidade de } \\
\text { uma aproximação, cada vez maior, da } \\
\text { compreensão da totalidade das relações sociais } \\
\text { em que estamos inseridos. É neste contexto que } \\
\text { ganha inteligibilidade o conceito de professor } \\
\text { prático reflexivo e outras adjetivações } \\
\text { semelhantes. }\end{array}$ & $\begin{array}{l}\text { mas, na sua opinião, de modo geral } \\
\text { “o ensino reflexivo, mesmo quando analisado } \\
\text { sob ob óticas teórico- } \\
\text { metodológicas, dá ênfase às preocupações } \\
\text { com a experiência } \\
\text { pessoal e com o desenvolvimento } \\
\text { profissional de professores" (Facci, 2003, } \\
\text { p.52). } \\
\text { Nesse sentido, indicamos, neste } \\
\text { espaço, que a ênfase em formar o } \\
\text { professorreflexivo, o professor-investigador, o } \\
\text { professor-prático-reflexivo, o } \\
\text { professorprofissional, } \\
\text { adjetivações, responde apenas aos diversos } \\
\text { constructos que têm, na verdade, a mesma raiz } \\
\text { epistemológica pragmática/praticista. Vários } \\
\text { são os autores que na atualidade se } \\
\text { contrapõem criticamente a estes constructos } \\
\text { (Edelstein,2000; Duarte,2003; Pimenta,2002; } \\
\text { Ghedin,2002; Serrão,2002; Moraes e } \\
\text { Torriglia,2003; Moraes, 2004; Facci,2003). } \\
\text { Mesmo assim, há ainda muitos aspectos não } \\
\text { explorados, alguns dos quais procuraremos } \\
\text { perseguir na continuidade desta pesquisa }\end{array}$ \\
\hline $\begin{array}{l}\text { Débora R. P. } \\
\text { Nunes }\end{array}$ & $\begin{array}{l}\text { Teoria, pesquisa e } \\
\text { prática em Educação: } \\
\text { a formação } \\
\text { do } \\
\text { professor- } \\
\text { pesquisador }\end{array}$ & Não encontrado & $\begin{array}{l}\text { A formação em pesquisa é o que permite, } \\
\text { na concepção desse autor, que o professor } \\
\text { desenvolva } \\
\text { uma consciência crítica de suas ações. } \\
\text { Vale ressaltar que essa formação científica não } \\
\text { deve ser impregnada por uma conotação } \\
\text { unicamente acadêmica, conforme argumentam } \\
\text { Lüdke e Cruz (2005), mas deve favorecer o } \\
\text { trabalho voltado para questões diárias das } \\
\text { salas de aula. } \\
\text { A formação profissional do professor- } \\
\text { pesquisador favorece, em última instância, a } \\
\text { proliferação de práticas pedagógicas eficazes. } \\
\text { Como profissional crítico, esse professor } \\
\text { torna-se } \\
\text { apto a comparar métodos de ensino, refutar } \\
\text { teorias } \\
\text { e produzir novos conhecimentos. }\end{array}$ \\
\hline $\begin{array}{l}\text { Bernadete A. } \\
\text { Gatti }\end{array}$ & $\begin{array}{l}\text { Formação de } \\
\text { professores no brasil: } \\
\text { Características } \\
\text { problemas }\end{array}$ & $\begin{array}{l}\text { No que concerne à formação de professores, é } \\
\text { necessária uma verdadeira } \\
\text { revolução nas estruturas institucionais } \\
\text { formativas e nos currículos } \\
\text { da formação. As emendas já são muitas. A } \\
\text { fragmentação formativa } \\
\text { é clara. É preciso integrar essa formação em } \\
\text { currículos articulados e voltados } \\
\text { a esse objetivo precípuo. A formação de } \\
\text { professores não pode ser } \\
\text { pensada a partir das ciências e seus diversos } \\
\text { campos disciplinares, como } \\
\text { adendo destas áreas, mas a partir da função } \\
\text { social própria à escolarização } \\
\text { - ensinar às novas gerações o conhecimento } \\
\text { acumulado e consolidar } \\
\text { valores e práticas coerentes com nossa vida } \\
\text { civil. } \\
\text { A formação de professores profissionais para a } \\
\text { educaçáo básica tem que partir de seu campo de } \\
\text { prática e agregar a este } \\
\text { os conhecimentos necessários selecionados } \\
\text { como valorosos, em seus fundamentos } \\
\text { e com as mediações didáticas necessárias, } \\
\text { sobretudo por se tratar } \\
\text { de formação para o trabalho educacional com }\end{array}$ & Não encontrado \\
\hline
\end{tabular}




\begin{tabular}{|c|c|c|c|}
\hline & & crianças e adolescentes. & \\
\hline $\begin{array}{l}\text { Dirce Mendes } \\
\text { da Fonseca }\end{array}$ & $\begin{array}{lr}\text { A } & \text { pedagogia } \\
\text { científica } & \text { de } \\
\text { Bachelard: } & \text { uma } \\
\text { reflexão a favor da } \\
\text { qualidade da prática } \\
\text { e da pesquisa } \\
\text { docente }\end{array}$ & $\begin{array}{l}\text { Na visão de Bachelard, a formação do } \\
\text { professor contemplaria uma prática pedagógica, } \\
\text { "uma metodologia consciente" que privilegiasse } \\
\text { uma pedagogia em ruptura com o conhecimento } \\
\text { usual. Assim, "de um modo mais } \\
\text { positivo, apreender-se-á a essência da } \\
\text { psicologia } \\
\text { do espírito científico na reflexão pela qual } \\
\text { as leis descobertas na experiência são pensadas } \\
\text { sob forma de regras aptas a descobrir novos } \\
\text { fatos" (Bachelard, 2000, p. 122). }\end{array}$ & Não encontrado \\
\hline $\begin{array}{l}\text { Antonio } \\
\text { Nóvoa }\end{array}$ & $\begin{array}{lr}\text { O professor } \\
\text { pesquisador } \\
\text { reflexivo } \\
\text { ( entrevista, salto } \\
\text { para o futuro) }\end{array}$ & Não encontrado & $\begin{array}{l}\text { O professor pesquisador e o professor } \\
\text { reflexivo, no fundo,correspondem a correntes } \\
\text { (conceitos) diferentes para dizer a mesma } \\
\text { coisa. São nomes distintos, maneiras } \\
\text { diferentes dos teóricos da literatura } \\
\text { pedagógica abordarem uma mesma realidade. } \\
\text { A realidade é que o professor pesquisador é } \\
\text { aquele que pesquisa ou que reflete sobre } \\
\text { a sua prática. Portanto, aqui estamos dentro do } \\
\text { paradigma do professor reflexivo. É evidente } \\
\text { que podemos encontrar dezenas de textos para } \\
\text { explicar a diferença entre esses conceitos, mas } \\
\text { creio que, no fundo, no fundo, eles fazem } \\
\text { parte de um mesmo movimento de } \\
\text { preocupação com um professor que é um } \\
\text { professor indagador, que é um professor } \\
\text { que assume a sua própria realidade escolar } \\
\text { como um objeto de pesquisa, como objeto de } \\
\text { reflexão, como objeto de análise [...] a } \\
\text { experiência por si só não é formadora } \\
\text { (NÓVOA, 2001, SP - } \\
\text { Entrevista concedida em } 13 \text { de setembro } 2001 \\
\text { Programa Salto Para o } \\
\text { Futuro!) }\end{array}$ \\
\hline
\end{tabular}




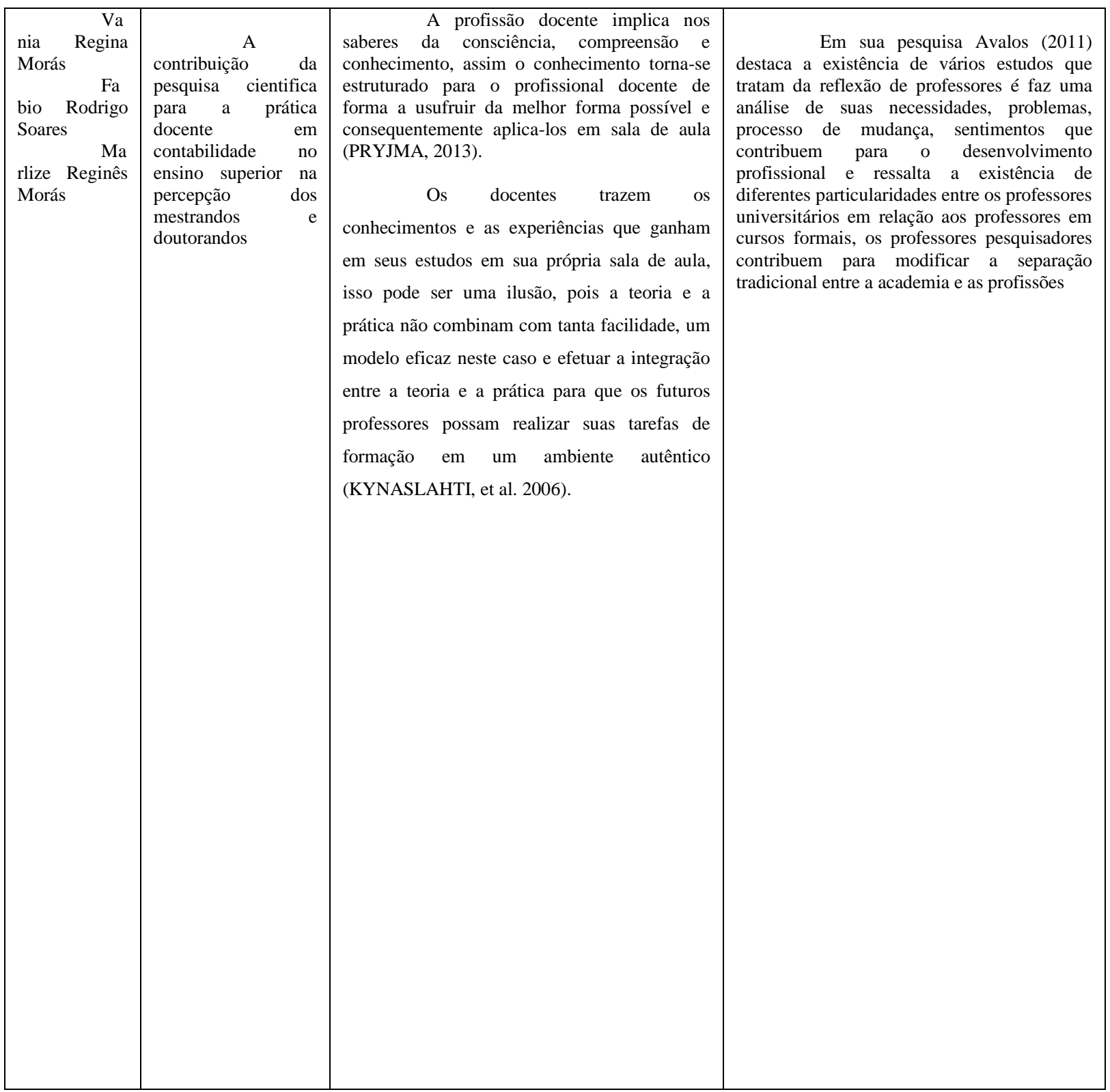




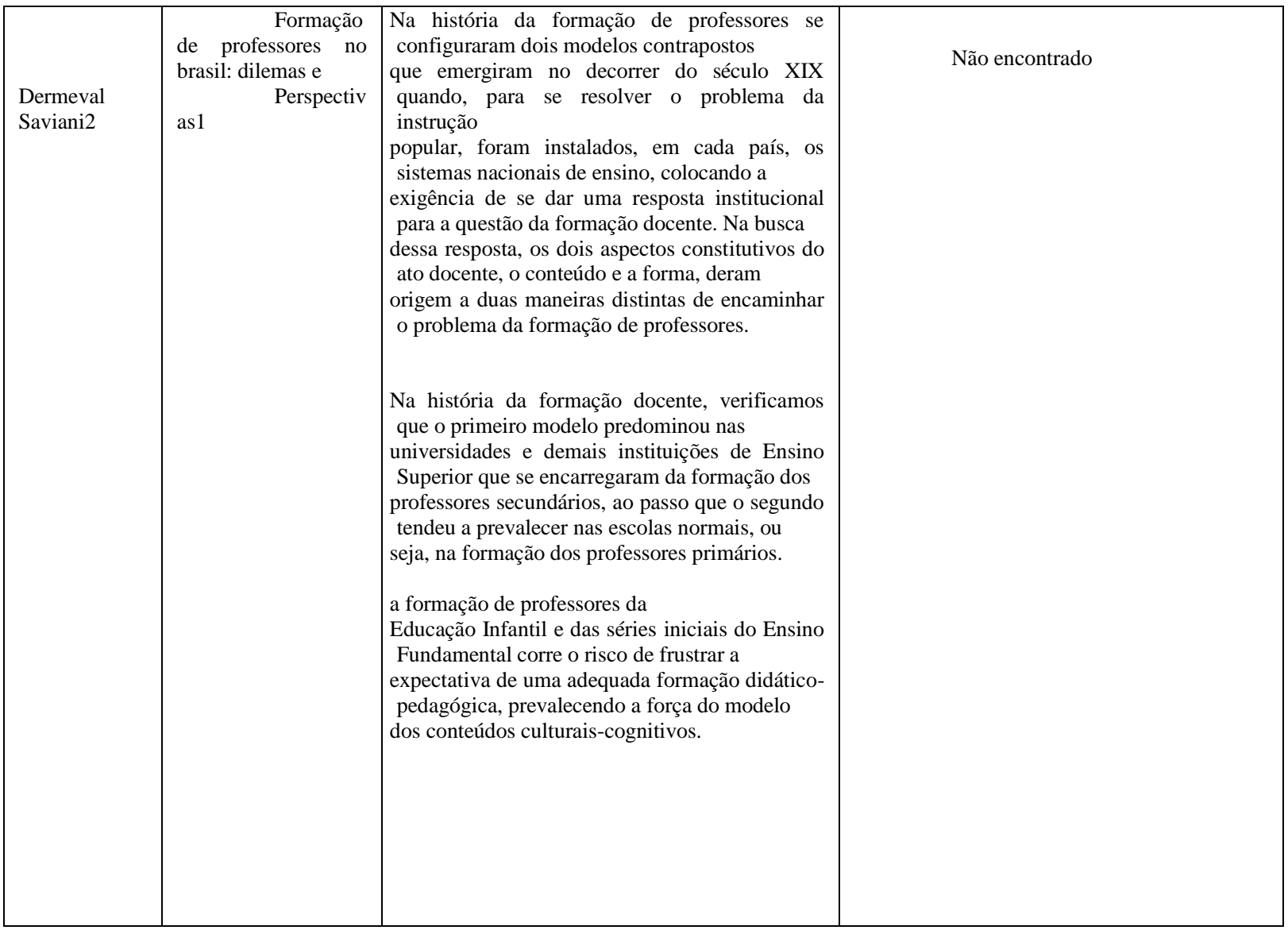




\section{REFERÊNCIAS BIBLIOGRÁFICAS}

ANDRE, Marli et al. Pesquisas sobre formação de professores: uma análise das racionalidades. Educação \& Linguagem, v. 14, p. 90-104, 2006.

GATTI, Bernadete Angelina.(Org.). O trabalho docente: avaliação, valorização, controvérsias. Campinas: SP: Autores Associados; São Paulo: Fundação Carlos Chagas, 2014b.

GATTI, B. A.; BARRETTO, E. S. S. Professores do Brasil: Impasses e Desafios. Brasília, Unesco, 2009.

GATTI, B. A; BARReTto, E. S. de S.; ANDRÉ, M. E. D. A. Políticas Docentes no Brasil: um Estado da Arte. Brasília, Unesco, 2011.

GATTI, Bernadete Angelina. A Construção da pesquisa em Educação no Brasil. Brasília: Plano, 2002.

NOVIKOFF, C. Pensar e Pesquisar: caminhos para o conhecer. In Revista Magistro. Vol. 1 Num.1, 2010a.

. Dimensões Novikoff: um constructo para o ensino-aprendizado da pesquisa. In

ROCHA, J. G. e NOVIKOFF, C. (orgs.).Desafios da práxis educacional à promoção humana na contemporaneidade. Rio de Janeiro: Espalhafato Comunicação, p. 211-242, 2010b. NOVIKOFF, C; MITHIDIERI, O. B.; SILVA, S. B. da. Formação humana/docente em tempos de contradiscursos: ética ferida? In NOVIKOFF, C.; GRISPUN, M. P. S. Z; DUTRA, R. (Orgs.) Desafios da práxis educacional: interdisciplinaridade, estética e ética. Salvador: Editora Pontocom, 2013

PIMENTA, Selma Garrido. Professor Reflexivo: construindo uma crítica. In: PIMENTA, Selma Garrido; GHEDIN, Evandro (orgas.). Professor Reflexivo no Brasil: gênese e crítica de um conceito. $3^{\text {a }}$ Ed., São Paulo: Cortez, p.17-57 S/P, 2009.

TOZONI-REIS, Marília Freitas de Campos. A pesquisa e a produção de conhecimentos: introdução à pesquisa em educação. Curso de pedagogia da Unesp. 2010. Disponível em: <http://www.acervodigital.unesp.br/handle/123456789/195> Acesso em: 10 Jun. 2017. 
NÓVOA, Antônio. O professor pesquisador e reflexivo.

In $\langle w w w . t v e b r a s i l . c o m / b r / s a l t o / e n t r e v i 09 / 10 / 2009>$. Entrevista concedida em 13 de setembro de 2001. Acesso em: 23/abr./2015. 